\title{
Antibacterial activities of plant-derived compounds and essential oils against Cronobacter strains
}

\author{
Anna Berthold-Pluta ${ }^{1} \cdot$ Lidia Stasiak-Różańska $^{2} \cdot$ Antoni Pluta $^{1} \cdot$ Monika Garbowska $^{3}$
}

Received: 24 October 2018 / Revised: 14 December 2018 / Accepted: 16 December 2018 / Published online: 28 December 2018

(c) The Author(s) 2018

\begin{abstract}
Essential oils (EOs) are liquid preparations produced from plant materials. Their use as inhibitors of the growth of spoilage and pathogenic microorganisms is a good alternative to the chemical additives in foods. The disc-diffusion method was used to screen the EOs from thyme, cinnamon, clove, peppermint, marjoram, cumin, rosemary, fennel, basil, lime, bergamot orange, orange, lemon, grapefruit, mandarin, cardamom, anise, and ginger, against 21 strains of Cronobacter species, including: $C$. sakazakii, $C$. muytjensii, $C$. turicensis, $C$. condimenti, and $C$. malonaticus. In addition, the minimum inhibitory concentration (MIC) and the maximum tolerable concentration (MTC) of thymol, trans-cinnamaldehyde, eugenol, and menthol were determined for five strains of Cronobacter spp. The most effective EOs were: thyme > cinnamon > marjoram. In turn, EOs from clove, cumin, and fennel had a moderate inhibiting effect against only some of the analyzed strains. The majority of the tested EOs: peppermint, rosemary, basil, cardamom, anise, ginger, and all EOs from citrus fruits were ineffective against all the studied strains.
\end{abstract}

Keywords Cronobacter spp. Essential oils $\cdot$ Thymol $\cdot$ Eugenol $\cdot$ Cinnamaldehyde $\cdot$ Menthol

\section{Introduction}

The Cronobacter genus bacteria are Gram-negative motile bacilli representing the Enterobacteriaceae family which includes microorganisms responsible for inducing the highest number of food poisonings in humans worldwide [1]. Currently, the following seven species: C. sakazakii, $C$. turicensis, $C$. malonaticus, $C$. muytjensii, $C$. universalis, $C$. dublinensis, and $C$. condimenti, have been classified to the

Anna Berthold-Pluta

anna_berthold@sggw.pl

1 Division of Milk Biotechnology, Department of Biotechnology, Microbiology and Food Evaluation, Faculty of Food Sciences, Warsaw University of Life Sciences, SGGW, Nowoursynowska 159C St, 02-787 Warsaw, Poland

2 Division of Food Biotechnology and Microbiology, Department of Biotechnology, Microbiology and Food Evaluation, Faculty of Food Sciences, Warsaw University of Life Sciences, SGGW, Nowoursynowska 159C St, 02-787 Warsaw, Poland

3 Prof. Wacław Dąbrowski Institute of Agricultural and Food Biotechnology, Inter-Department Problem Group for Dairy Industries, Rakowiecka 36 St, 02-532 Warsaw, Poland
Cronobacter genus [2, 3]. Among them, $C$. turicensis, $C$. sakazakii, C. malonaticus, and C. universalis are of clinical significance [4]. The most extensively described species from the Cronobacter genus is $C$. sakazakii, which is an opportunistic pathogen that may cause bacteremia, sepsis, meningitis, and necrotizing enterocolitis in neonates [5-7]. Cronobacter infections also occur in adults (especially immunocompromised, suffering from serious illnesses, and elderly patients), and cause the following symptoms: conjunctivitis, biliary sepsis, urosepsis, appendicitis, wound infections, and pneumonia [4]. It has the ability to adapt to several environmental stresses including drying, heating (though it does not survive pasteurization), chilling, and to osmotic stresses. In addition, it easily colonizes various environments due to the capability for biofilm formation, which facilities its attachment to stainless steel, glass, silicon, latex, polycarbonate, and polyvinyl chloride (PVC) $[8$, 9]. All these traits allow these microorganisms to survive under conditions of food production processes [10, 11]. Bacteria belonging to the genus Cronobacter have been isolated from various food products, including these intended for infants and children, from dairy and meat products, plantderived foods, water, and others [12-20]. 
Natural antimicrobial agents derived from plant sources (for example, the essential oils-EOs) have been recognized and used for centuries in food preservation as well as for food flavor enhancement. While choosing EO dose added to a food product, attention should be paid not only to the expected technological effect of EO but also to sensory changes its components may evoke in a given food product. As food additives, the EOs may be used as food preserving agent, as they extend storage time of food products or enter into synergistic reactions with the preserving agents present in food to enhance their efficacy $[21,22]$.

Several plant-derived EOs have been demonstrated to display the antimicrobial properties [23, 24], and a variety of their active components have been identified. EOs contain multiple substances which exhibit antibacterial activity against pathogenic bacteria, Listeria monocytogenes, Salmonella Typhimurium, Escherichia coli O157:H7, Bacillus cereus, and Staphylococcus aureus [25-30]. Only a few studies, however, have investigated the inhibitory effects of EOs and carvacrol, thymol, eugenol, and cinnamic acid or trans-cinnamaldehyde against $C$. sakazakii [10,31-33]. The knowledge about the potential susceptibility of other species from the genus Cronobacter to EOs and active substances of plant origin is still very scanty.

The first goal of this study was to determine the antimicrobial activity of 18 selected plant EOs against 21 strains representing five species from the genus Cronobacter. The second objective was to establish the susceptibility of the five tested species: Cronobacter sakazakii, C. malonaticus, C. muytjensii, C. turicensis, and C. condimenti to the major active substances of thyme, cinnamon, clove, and peppermint oils, i.e., to thymol, trans-cinnamaldehyde, eugenol, and menthol, respectively. Effects of some of these antimicrobials have not been reported previously. The manuscript is also the first to provide data on the susceptibility of $C$. muytjensii, $C$. turicensis, and C. condimenti species to EOs.

\section{Materials and methods}

\section{Essential oils and crude plant-derived substances}

The study was conducted with 18 essential oils from the following plants: Thymus vulgaris (thyme), Cinnamomum aromaticum (cinnamon), Syzygium aromaticum (clove), Mentha piperita (peppermint), Origanum marjorana (marjoram), Carum carvi (cumin), Rosmarinus officinalis (rosemary), Foeniculum vulgare (fennel), Ocimum basilicum (basil), Citrus aurantifolia (lime), Citrus aurantium subsp. bergamia (bergamot orange), Citrus sinensis (orange), Citrus limon (lemon), Citrus paradisi (grapefruit), Citrus reticulate var. madurensis (mandarin), Elettaria cardamomum (cardamom), Pimpinella anisum (anise), and Zingiber officinale (ginger). They were obtained from FSZ Pollena-Aroma, Nowy Dwór Mazowiecki, Poland.

Analyses were also conducted for the four following active substances of the essential oils: thymol, trans-cinnamaldehyde, eugenol, and menthol; all obtained from Sigma-Aldrich, Poland.

\section{Microbial strains}

Strains to be analyzed in this study were isolated from market products of plant origin by Berthold-Pluta et al. [13] (the isolates were subjected to genetic identification and differentiation by $16 \mathrm{~S}$ rDNA sequencing, PCR-RFLP analysis, and RAPD-PCR). They included: 13 strains of Cronobacter sakazakii (s12, s14, s21, s22, s41, s42, s44, s45, s47, s48, lv25, lv27, lv28), four strains of C. muytjensii (s16, s34, s50, s51), two strains of C. turicensis (lv53, lv54), 1 strain of $C$. condimenti (s37), and one strain of C. malonaticus (lv31) (Table 1). The tested strains were stored at $-48{ }^{\circ} \mathrm{C}$. Prior to use, they were grown freshly on tryptone soya broth (TSB, Argenta, Poland).

Table 1 Tested Cronobacter strains

\begin{tabular}{|c|c|c|c|}
\hline Species & strain & Origin (product) & References \\
\hline \multirow[t]{13}{*}{ C. sakazakii } & $\mathrm{s} 12$ & Alfalfa sprouts & \multirow{21}{*}{$\begin{array}{l}\text { Berthold-Pluta et al. } \\
\text { [11] }\end{array}$} \\
\hline & s14 & Alfalfa sprouts & \\
\hline & s41 & Sunflower sprouts & \\
\hline & $\mathrm{s} 42$ & Sunflower sprouts & \\
\hline & s44 & Mix of sprouts & \\
\hline & s45 & Mix of sprouts & \\
\hline & $\mathrm{s} 21$ & Leek sprouts & \\
\hline & $\mathrm{s} 22$ & Leek sprouts & \\
\hline & s47 & Mix of sprouts & \\
\hline & s 48 & Mix of sprouts & \\
\hline & $\operatorname{lv} 25$ & Rucola & \\
\hline & $\operatorname{lv} 27$ & Endive escarola & \\
\hline & $\operatorname{lv} 28$ & Rucola & \\
\hline \multirow[t]{4}{*}{ C. muytjensii } & s16 & Lentil sprouts & \\
\hline & s34 & Broccoli sprouts & \\
\hline & s50 & Lentil sprouts & \\
\hline & s51 & Lentil sprouts & \\
\hline \multirow[t]{2}{*}{ C. turicensis } & $\operatorname{lv} 53$ & $\begin{array}{l}\text { Mix of leaf vegeta- } \\
\text { bles }\end{array}$ & \\
\hline & $\operatorname{lv} 54$ & $\begin{array}{l}\text { Mix of leaf vegeta- } \\
\text { bles }\end{array}$ & \\
\hline C. condimenti & s37 & Small radish sprouts & \\
\hline C. malonaticus & $\operatorname{lv} 31$ & Lamb's lettuce & \\
\hline
\end{tabular}


Screening of antimicrobial activity of plant essential oils

A disc-diffusion assay described by Rusenova and Parvanov [34] with small modifications was used in the study. The bacterial inoculum was prepared from an overnight culture on tryptone soya agar (TSA, Argenta, Poland). Colonies were directly suspended in $0.85 \%$ saline to obtain turbidity comparable to that of the $0.5 \mathrm{McF}$ arland standard (approximately $\left.8 \log \mathrm{CFU} \mathrm{mL} \mathrm{m}^{-1}\right)$. Aliquots $(0.1 \mathrm{~mL})$ of the inoculum were spread over the surface of pre-dried tryptone soya agar plates with a sterile spreader. Sterile $6 \mathrm{~mm}$ filter paper discs (BTL Sp. z o.o., Poland) were placed on the plates and $10 \mu \mathrm{L}$ portions of the essential oils were added immediately. Sterile paper discs were used as the control. The plates were left for $30 \mathrm{~min}$ at room temperature to allow oil diffusion and then were incubated at $35{ }^{\circ} \mathrm{C}$ for $24 \mathrm{~h}$. Diameters of inhibition zone were measured in triplicate in millimeters. The scale of measurement was as follows: strong inhibition-zone of inhibition $\geq 20 \mathrm{~mm}$ (disc diameter included), moderate inhibition-zone $<20-12 \mathrm{~mm}$, and no inhibition-zone $<12 \mathrm{~mm}$. The assay was carried out in triplicate. Values are presented as means $\pm \mathrm{SD}$.

\section{Determination of the minimum inhibitory concentration and maximum tolerable concentration of thymol, trans-cinnamaldehyde, eugenol, and menthol against Cronobacter strains}

The susceptibility of the five selected strains of the Cronobacter genus bacteria (C. sakazakii lv27, C. malonaticus lv31, C. muytjensii s50, C. turicensis lv53, and C. condimenti s37) to the active substances of essential oils was evaluated with a slightly modified method of Oussalah et al. [35]. Prior to the experiment, working cultures were prepared by subculturing $100 \mu \mathrm{L}$ of each culture in $9 \mathrm{~mL}$ of TBS, and incubated at $35^{\circ} \mathrm{C}$ for $24 \mathrm{~h}$.

Ten final concentrations of the tested substances $[0.000 \%$, $0.003 \%, 0.006 \%, 0.013 \%, 0.025 \%, 0.05 \%, 0.1 \%, 0.2 \%, 0.4 \%$, and $0.8 \%$ (vol/vol)] were obtained by adding their various volumes from the $10 \%$ (wt/vol) suspension in $96 \%$ ethanol to the molten Mueller Hinton Agar (MHA, Argenta, Poland) $(15 \mathrm{~mL})$. Immediately after thorough mixing, the $\mathrm{MH}$ agar with an appropriate amount of the tested substance was poured onto sterile Petri plates and left to solidify $\left(30^{\circ} \mathrm{C}\right.$, $3 \mathrm{~h}$ ). Then, $100 \mu \mathrm{L}$ of each diluted culture was individually spread on the surface of the plates. Dilution of the Cronobacter culture was adjusted to ensure the number of colonies grown after plates' incubation in the range from 30 to 150 . The suspension of microorganisms was carefully spread onto the plate using a sterile spreader, until its complete absorption. The positive control consisted of MHA without the tested substances, inoculated with the diluted medium culture. Non-inoculated plates containing the tested substances served as the negative control. The test and control plates were then incubated at $35{ }^{\circ} \mathrm{C}$ for $48 \mathrm{~h}$. Results obtained allowed determining the minimum inhibitory concentration (MIC; concentration of the tested active substance at which no growth of the test strain was observed) and maximum tolerable concentration (MTC; the maximum concentration of the analyzed active substance at which the number of grown colonies of the test strain did not differ significantly from the number of colonies grown on the plate with the medium not containing the analyzed active substance). Determinations were made in triplicate.

\section{Results and discussion}

\section{Antimicrobial activity of plant essential oils against Cronobacter strains}

The zones of inhibition resulting from the exposure of Cronobacter strains to the plant essential oils (10 $\mu \mathrm{L} / \mathrm{disc})$ measured using the disc-diffusion method are shown in Table 2.

In general, the plant extracts showed a high antibacterial activity against Gram(+) bacteria and a lower activity against Gram(-) bacteria. The observed resistance of the Gram(-) bacteria could be due to the permeability barrier provided by the cell wall or to the membrane accumulation mechanism. The hydrophilic cell wall structure of Gram(-) bacteria, constituted essentially by a lipopolysaccharide, blocks the penetration of hydrophobic components of oils [23].

The greatest zones of growth inhibition of bacterial strains from the genus Cronobacter were observed in the case of the thyme oil, i.e., from 15.8 to $31.8 \mathrm{~mm}$. It turned out to be strongly inhibitory (growth inhibition zone $>20 \mathrm{~mm}$ ) against 13 strains. The most susceptible strains to this EO, i.e., the strains with the greatest inhibition zones, included these from the species $C$. muytjensii, and the mean diameter of their growth inhibition zone reached $27.1 \mathrm{~mm}$. More resistant to the effects of thyme oil appeared to be strains of $C$. turicensis, $C$. malonaticus, and $C$. condimenti species (mean diameter of growth inhibition zone of ca. $17 \mathrm{~mm}$ ).

The major components of thyme EO include: thymol, $p$-cymene, $\gamma$-terpinene, and also carvacrol, linalool, and $\beta$-caryophyllene [36, 37]. Among these, the greatest load of data about the antimicrobial activity is available for thymol and carvacrol. The mechanism of their action consists in disrupting the cytoplasmic membrane of a cell, which increases its permeability and depolarizes its potential [38]. Using the disc-diffusion method, Soković et al. [37] demonstrated growth inhibition zones of $22 \mathrm{~mm}$ for both Enterobacter cloacae and E. coli exposed to thyme oil. 


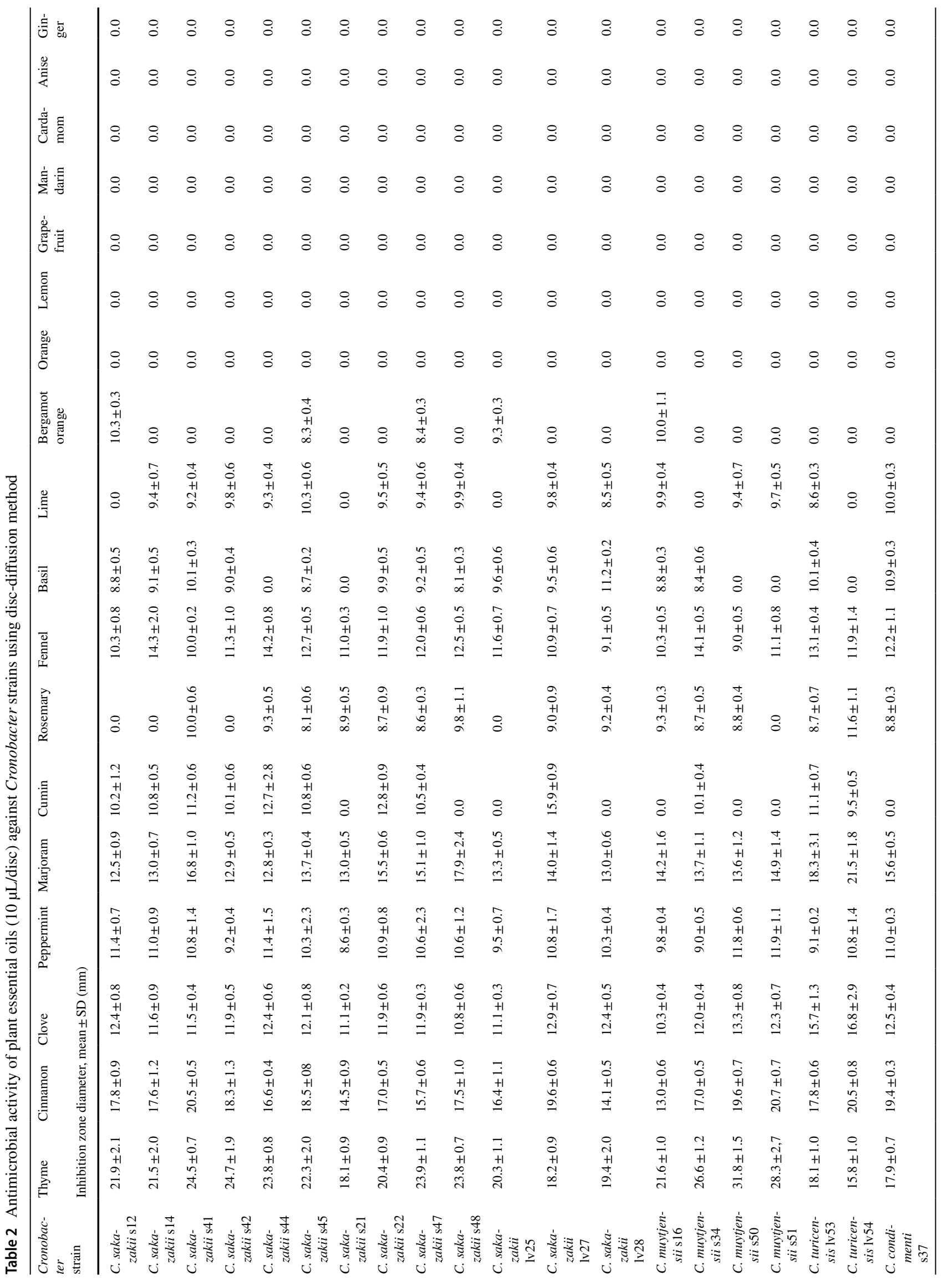


Cinnamon oil contains many substances, such as cinnamaldehyde (and trans-cinnamaldehyde), cinnamate, cinnamic acid, cinnamyl acetate, eugenol, L-borneol, camphor, caryophyllene oxide, $\beta$-caryophyllene, $\alpha$-terpineol, and many others, which protect plants against competitors and pathogens [39]. Both oil and pure cinnamaldehyde were equally effective in inhibiting the growth of various bacteria including the Gram-positive ( $S$. aureus) and the Gram-negative ones (E. coli, Enterobacter aerogenes, Proteus vulgaris, Pseudomonas aeruginosa, Vibrio cholerae, and S. Typhimurium), and fungi including yeasts (Candida spp.) and molds (Aspergillus spp. and Fusarium spp.). The MICs of both oil and cinnamaldehyde ranged from 0.0075 to $0.06 \%$ for bacteria, from 0.01 to $0.045 \%$ for yeasts, and from 0.0075 to $0.015 \%$ for molds [40].

Significant susceptibility to cinnamon oil (growth inhibition zone $>20 \mathrm{~mm}$ ) was demonstrated for the three following strains: $C$. muytjensii s51, C. sakazakii s41, and C. turicensis lv54, while the growth of the other strains was moderately inhibited by this EO. An inhibiting effect of cinnamon oil on $C$. sakazakii was also shown by Al-Nabulsi et al. [31] (diameters of growth inhibition zones ranged from 32 to $40 \mathrm{~mm}$ ). Literature data on the susceptibility of other bacterial species, e.g., L. monocytogenes, to this essential oil also confirm its strong antimicrobial properties [34, 35].

The clove oil turned out a poor growth inhibitor (growth inhibition zone $<12 \mathrm{~mm}$ ) for 9 out of the 21 tested strains. Growth inhibition diameters measured for the other analyzed strains ranged from 12.1 to $16.8 \mathrm{~mm}$, and their average values reached ca. $12 \mathrm{~mm}$ for strains of $C$. sakazakii, $C$. condimenti, C. muytjensii, and C. malonaticus species, as well as $16 \mathrm{~mm}$ for strains of $C$. turicensis species. Data concerning the antimicrobial properties of clove oil against Cronobacter are very scanty. Only Fraňková et al. [33] reported the MIC of clove oil at $0.05 \%$ for C. sakazakii and C. malonaticus.

Among the volatile components of clove oil, eugenol and $(-)$ - $\alpha$-selinene occur in the highest concentrations, but also cis- $\alpha$-bisabolene, ocimene, santolinatriene, and humulene are its major volatiles, though they are present in lower concentrations [41]. Biofilm inhibition experiments showed that a clove extract inhibited biofilm formation by $C$. sakazakii isolates [42]. Biofilm formation plays a significant part in the pathogenesis of $C$. sakazakii, and development of these biofilms is based on the signal-mediated quorum sensing (QS) system. Therefore, an interference with QS may prevent the development of bacterial biofilms and further infections [42].

None of the tested strains was susceptible to the peppermint oil; diameters of their growth inhibition zones ranged from 8.0 to $11.9 \mathrm{~mm}$. Their resistance to this EO was similar (mean growth inhibition zone diameter reached ca. $10 \mathrm{~mm}$ for strains of the same species), except for the strain C. malonaticus lv31 which turned out to be little more 
resistant (growth inhibition zone diameter of $8.0 \mathrm{~mm}$ ). The bactericidal properties of the peppermint oil were confirmed by Rusenova and Parvanov [34]; diameters of growth inhibition zones measured for L. monocytogenes and Bacillus licheniformis reached 18 and $27.4 \mathrm{~mm}$, respectively. This EO evoked the inhibiting effect also on other bacteria, i.e., S. aureus, E. coli, and P. aeruginosa [37, 43, 44]. The antimicrobial potential of the Mentha piperita essential oil was also observed by Tyagi and Malik [45] against the strains of E. coli (growth inhibition zone of $10 \mathrm{~mm}$ ) and Pseudomonas spp. (11-14 mm).

The vast majority of the tested strains exhibited moderate susceptibility to the marjoram oil; mean growth inhibition diameters ranged from 12.5 to $17.9 \mathrm{~mm}$. Only both strains of C. turicensis-lv53 and lv54 appeared to be more susceptible (growth inhibition zones of 18.3 and $21.5 \mathrm{~mm}$, respectively). The antimicrobial activity of the marjoram oil against $E$. coli (growth inhibition zone of $14 \mathrm{~mm}$ ) and B. cereus $(16 \mathrm{~mm})$ was reported by Tserennadmid et al. [46]. In turn, Rusenova and Parvanov [34] demonstrated its inhibiting effect on such species as. S. aureus, L. monocytogenes, B. lichenformis, E. faecalis, and E. aerogenes, whose growth inhibition diameters reached 17.7, 14.3, 19.3, 13.7 , and $13.0 \mathrm{~mm}$, respectively. The major components of the marjoram essential oil include: $\gamma$-terpinene, sabinene, linalool, and linalyl-acetate [46]. Literature data on its antibacterial properties are scanty. Soković et al. [37] used the disc-diffusion method to analyze the antibacterial activity of, i.a., linalyl-acetate against $E$. coli and E. cloacae and noted 8-mm zones of their growth inhibition.

In our study, only four strains (C. sakazakii s44, $C$. sakazakii s22, C. sakazakii lv27, and C. malonaticus lv31) turned out to be moderately resistant to the cumin essential oil (diameters of growth inhibition zones ranging from 12.7 to $15.9 \mathrm{~mm}$ ), whereas eight strains remained unaffected by this EO (lack of growth inhibition zones). The antibacterial activity of Carum carvi essential oil could be attributed to its polyphenolic compounds. In turn, the antibacterial activity of polyphenols has been ascribed to the inhibition of synthesis of DNA, RNA and other related macromolecules [30]. Sixteen compounds were identified in C. carvi EO, out of which cuminaldehyde (22\%) was the principal component followed by $\gamma$-terpinene (18\%), $\gamma$-terpinene-7-al (15\%), and $p$-cymene (8\%) [47]. Fraňková et al. [33] demonstrated a moderate antibacterial activity of its components, i.e. $\gamma$-terpinene and $p$-cymene, against $C$. sakazakii and $C$. malonaticus.

The rosemary essential oil had no inhibitory effect on the tested strains regardless of the species. Growth inhibition zones with diameters ranging from 8.1 to $11.6 \mathrm{~mm}$ were demonstrated for 16 strains. No growth inhibition zones were observed in the case of the five other strains, including four from the species C. sakazakii (s12, s14, s42, and lv25) and one from the species $C$. muytjensii (s51). Our results confirmed earlier findings reported by Al-Nabulsi et al. [31], who demonstrated a negligible antibacterial activity of the rosemary essential oil against the Cronobacter genus bacteria (growth inhibition zones up to $8 \mathrm{~mm}$ ).

Considering the Gram(+) bacteria, the MIC of the rosemary EO was $0.5 \%$ for L. monocytogenes and S. aureus, and $0.06 \%$ for B. cereus. Up to $1 \%$ of this EO had no effect on the Gram(-) bacteria like E. coli, or Salmonella Enteritidis [48]. The major constituents of rosemary EO were reported to be 1,8-cineole, $\alpha$-pinene, myrcene, camphor, and camphene [28, 49]. Jiang et al. [49] also reported that the MIC values of rosemary EO, 1,8-cineole and $\alpha$-pinene for E. coli accounted for $0.3 \%,>4.0 \%$, and $1.0 \%$, respectively. The effectiveness of 1,8-cineole and $\alpha$-pinene against $E$. coli was also confirmed by Ojeda-Sana et al. [28] who additionally demonstrated a lack of their antibacterial activity against Gram(+) bacteria like $S$. aureus and E. faecalis.

The major components of fennel EO have been reported to be trans-anethole, fenchone, estragole (methyl chavicol), and $\alpha$-phellandrene [50,51]. The fennel EO has been shown to exhibit a moderately antibacterial effect against foodborne pathogens such as E. coli, S. aureus, and L. monocytogenes $[50,52,53]$. In our study, this EO also exhibited a moderate antibacterial activity against nine strains (growth inhibition zones from 12.0 to $14.8 \mathrm{~mm}$ ). In the case of the other Cronobacter spp. strains, diameters of growth inhibition zones ranged from 9.0 to $11.9 \mathrm{~mm}$. These results confirm earlier findings reported by Al-Nabulsi et al. [31], who demonstrated very weak inhibiting properties of the fennel EO against $C$. sakazakii (width of growth inhibition zones was less than $1 \mathrm{~mm}$ ). In turn, Elgayyar et al. [54] showed a strongly inhibiting effect of this EO on S. aureus and Yersinia enterocolitica; diameters of their growth inhibition zones reached 38 and $57 \mathrm{~mm}$, respectively. The fennel EO was also reported to elicit an inhibiting effect on $B$. cereus [29].

Zones of growth inhibition induced by the basil essential oil were observed for 16 out of the 21 tested strains; their diameters ranged from 8.1 to $11.2 \mathrm{~mm}$. In contrast, this EO had no inhibiting effect on C. sakazakii s44 and s21, C. muytjensii $\mathrm{s} 50$ and $\mathrm{s} 51$, and $C$. turicensis 1v54 strains. Literature data differ slightly from results obtained in our study and show the antimicrobial activity of basil EO against $E$. coli and E. cloacae-diameters of their growth inhibition zones reached 14 and $12 \mathrm{~mm}$, respectively [37]. In turn, Elgayyar et al. [54] demonstrated the antimicrobial activity of basil EO against $S$. aureus and $Y$. enterocolitica, whereas Tajkarimi et al. [29] against B. cereus.

As reported by Soković et al. [37], the major components of the EO from Ocimum basilicum include linalool (ca. $69 \%$ ), $\alpha$-cadinol, $\gamma$-cadinene, methyl chavicol, trans$\beta$-guaiene, and eugenol. Zones of E. coli and E. cloacae 
growth inhibition by linalool were $12 \mathrm{~mm}$ in diameter, and zone of Bacillus subtilis growth inhibition was $20 \mathrm{~mm}$ in diameter [37]. In turn, eugenol and linalool inhibited the growth of $C$. sakazakii and C. malonaticus [33].

Among the six analyzed EOs from citrus fruits, i.e., from: Citrus aurantifolia (lime), Citrus aurantium subsp. bergamia (bergamot orange), Citrus sinensis (orange), Citrus limon (lemon), Citrus paradisi (grapefruit), and Citrus reticulate var. madurensis (mandarin), as many as 4-from orange, lemon, grapefruit, and mandarin-had no effect on the growth of Cronobacter (no growth inhibition zones). Diameters of growth inhibition zones of 16 strains of Cronobacter induced by the lime EO ranged from 8.5 to $10.3 \mathrm{~mm}$, whereas no growth inhibition zones were observed for five tested strains (C. sakazakii s12, C. sakazakii s21, C. sakazakii lv25, C. muytjensii s34, and C. turicensis lv54). In turn, the bergamot essential oil inhibited the growth of four strains from the species $C$. sakazakii (s12, s45, s47 and lv25), $C$. muytjensii s16, and C. malonaticus lv31 (with diameters of growth inhibition zones ranging from 8.3 to $12.0 \mathrm{~mm}$ ), whereas it had no effect on the growth of the remaining 15 strains of Cronobacter.

Essential oils from citrus plants contain certain components that are typical of all plants from this group, such as: limonene and pinene ( $\alpha$ - and $\beta$-), but also other compounds present in smaller amounts depending on species, such as: sabinene, myrcene, and telinene in lime EO [47], $\gamma$-terpinene [37], and linalool [25] in lemon EO, and citral in orange EOs [25].

Lemon and orange essential oils exhibited weak antibacterial properties against E. coli and E. cloacae [37]. Fisher and Phillips [25] demonstrated that lemon and orange oils had week inhibitory effects on E. coli and Campylobacter jejuni when assessed with the disc-diffusion method and also, likewise in our study, that bergamot oil was the most effective of the tested citrus essential oils. Fraňková et al. [33] showed an inhibiting effect of limonene $(\mathrm{MIC}=0.3 \%)$ and weaker effects of $\alpha$ - and $\beta$-pinene (MIC $>0.5 \%$ ) on C. sakazakii and C. malonaticus, whereas Shi et al. [55] reported the growth inhibition of $C$. sakazakii by citral.

All analyzed strains from the genus Cronobacter were completely resistant to the cardamom, anise, and ginger essential oils (lack of growth inhibition zones). Only sparse reports are available in the literature on the antimicrobial activity of these EOs. Al-Nabulsi et al. [31] showed no inhibiting effect of anise EO on strains of the C. sakazakii species, whereas Inouye et al. [56] demonstrated a significantly weaker effect of the major component of cardamom oil—camphor-on growth inhibition of Gram(-) bacteria compared to cinnamaldehyde and thymol. As reported by Bellik [57], compounds of the ginger essential oil which exhibited the antibacterial activity were more effective against $E$. coli, B. subtilis, and $S$. aureus, than against $B$. cereus. In turn, Konakchiev et al. [58] demonstrated a weak effect of the ginger EO on growth inhibition of both $\operatorname{Gram}(+)$ and $\operatorname{Gram}(-)$ bacteria.

\section{MIC and MTC of thymol, trans-cinnamaldehyde, eugenol, and menthol against Cronobacter strains}

Table 3 presents determined values of the maximum tolerable concentration (MTC) and minimum inhibitory concentration (MIC) of EO components for five strains of Cronobacter genus bacteria.

The analyzed strains were tolerant to thymol-being the major component of thyme $\mathrm{EO}$, in its concentration ranges from 0.013 to $0.025 \%$ (MTC). In turn, the MIC of thymol reached $0.05 \%$ for all tested strains. Lee and Jin [10] demonstrated an inhibiting effect of thymol on two strains of Cronobacter (MIC 0.019\%). In addition, Fraňková et al. [33] noted a similar inhibiting activity of thymol against $C$. sakazakii and C. malonaticus (MIC 0.02\%). Literature data confirm also the inhibiting effect of thymol on other bacterial species, e.g., thymol was reported to inhibit the growth of S. Typhimurium and E. coli (MIC $0.02 \%$ and $0.04 \%$, respectively) $[59,60]$.

Equally strong antimicrobial activity was found in our study for trans-cinnamaldehyde. Its MTC and MIC values ranged from 0.025 and $0.05 \%$ (C. sakazakii lv27, $C$. malonaticus $1 \mathrm{v} 31$, and $C$. muytjensii s50) to $0.05 \%$ and $0.1 \%$, respectively ( $C$. turicensis $\operatorname{lv} 53$ and $C$. condimenti s37). These values are slightly higher from trans-cinnamaldehyde concentrations inducing growth inhibition of $C$. malonaticus and C. sakazakii bacteria, i.e., MIC from 0.025 to $0.03 \%$,
Table 3 MIC (\%) and MTC (\%) values of the analyzed components of essential oils determined for strains of the Cronobacter genus bacteria

\begin{tabular}{|c|c|c|c|c|c|c|c|c|}
\hline \multirow[t]{2}{*}{ Strain } & \multicolumn{2}{|c|}{ Thymol } & \multicolumn{2}{|c|}{$\begin{array}{l}\text { Trans-cinnamalde- } \\
\text { hyde }\end{array}$} & \multicolumn{2}{|c|}{ Eugenol } & \multicolumn{2}{|c|}{ Menthol } \\
\hline & MTC & MIC & MTC & MIC & MTC & MIC & MTC & MIC \\
\hline C. sakazakii lv27 & 0.013 & 0.05 & 0.025 & 0.05 & 0.05 & 0.2 & 0.4 & 0.8 \\
\hline C. malonaticus $\operatorname{lv} 31$ & 0.025 & 0.05 & 0.025 & 0.05 & 0.05 & 0.1 & 0.2 & 0.8 \\
\hline C. muytjensii s50 & 0.025 & 0.05 & 0.025 & 0.05 & 0.05 & 0.1 & 0.2 & 0.8 \\
\hline C. turicensis lv53 & 0.013 & 0.05 & 0.05 & 0.1 & 0.05 & 0.2 & 0.2 & 0.4 \\
\hline C. condimenti $\mathrm{s} 37$ & 0.013 & 0.05 & 0.05 & 0.1 & 0.1 & 0.2 & 0.4 & 0.8 \\
\hline
\end{tabular}


respectively [33]. The MIC of trans-cinnamaldehyde was also determined in reconstituted milk for infants and ranged from 0.3 to $0.5 \%$ depending on treatment temperature and time [32]. In turn, cinnamic acid was found to inhibit the growth of the Cronobacter genus bacteria at the concentration of $0.07 \%$ [10].

Trans-cinnamaldehyde is an unsaturated aldehyde. It has an acrolein group ( $\alpha, \beta$-unsaturated carbonyl moiety) in its molecule which is responsible for its antibacterial activity [39]. The mechanism of its antibacterial effect in, e.g., C. sakazakii, involves the downregulation of $\mathrm{F}_{1} \mathrm{~F}_{0}$-ATPase which leads to the inhibition of ATP synthesis. The $\mathrm{F}_{1} \mathrm{~F}_{0}$-ATPase complex is a reversible proton-translocating pump that may extrude protons from the cytoplasm and assists in the regulation of cytoplasmic $\mathrm{pH}$ [61]. Other mechanisms of trans-cinnamaldehyde action include perturbing the cell membrane and altering the lipid profile of the membrane [39]. Trans-cinnamaldehyde is able to inhibit guanosine triphosphate (GTP)-dependent FtsZ polymerization, which is the key process during cell division [62]. In addition, it has the ability to suppress gene expression of membrane porins (OmpA, OmpC, and OmpR), and amino acid transporters, which impairs the active transport through the bacterial cell membrane [61, 63]. Amalaradjou and Venkitanarayanan [61] demonstrated that trans-cinnamaldehyde can reduce the resistance to osmotic stress and desiccation in C. sakazakii. Its sub-inhibitory concentrations caused a significant reduction in both motility of $C$. sakazakii cells and their biofilm formation capability, which was attributable to the downregulation of the genes associated with the flagellar apparatus (fliD, flgJ, motA, and motB) [63].

Trans-cinnamaldehyde (or cinnamaldehyde) has often been addressed in scientific research considering its ability to inhibit the growth of microorganisms. Hill et al. [64] reported this component of the cinnamon EO to inhibit the growth of $S$. Typhimurium when used in the concentration of $0.04 \%$. The antimicrobial effects of cinnamaldehyde were also studied against bacteria of $E$. coli and $S$. aureus species [34], and the determined MIC values reached $0.015 \%$ and $0.03 \%$, respectively. The susceptibility of these bacteria to cinnamaldehyde was also reported by Ye et al. [65] (MIC $0.03 \%$ ).

Eugenol (4-allyl-2-methoxyphenol) is a phenol naturally occurring in an EO extracted from cloves. The basic mechanism of its antimicrobial effect involves disruption of the cytoplasmic membrane, which increases its non-specific permeability (referred to as the phenomenon of hyperpermeability). It leads to the release of ions and loss of other cellular contents, including the intracellular proteins, which ultimately ends with cell death [66]. The antimicrobial activity of eugenol against pathogenic microorganisms has been widely discussed in the literature. In studies with $S$. Typhimurium, the MIC of eugenol ranged from $0.05 \%$ [59] to $0.1 \%$ [64]. In turn, Filgueiras and Vanetti [67] analyzed its effects on L. monocytogenes and determined its MIC at $0.1 \%$. Eugenol has been reported to exhibit the antimicrobial activity also against $E$. coli, and its MIC value determined for these bacteria ranged from 0.04 to $0.16 \%[59,60]$.

Tolerance of the analyzed strains to eugenol fluctuated between 0.05 and $0.1 \%$ (MTC). The least susceptible to this major compound of clove EO in the medium was the C. condimenti $\mathrm{s} 37$ strain which tolerated the addition of eugenol in the concentration of $0.1 \%$. The MIC values of eugenol ranged from 0.1 to $0.2 \%$. Fraňková et al. [33] reported its similar MIC value $(0.1 \%)$ for strains of $C$. malonaticus and C. sakazakii bacteria. The antibacterial properties of eugenol against bacteria from the genus Cronobacter were also investigated by Lee and Jin [10], who determined its MIC at $0.082 \%$.

Menthol turned out to be an EO component with the weakest antibacterial activity. Development of the tested strains was inhibited at menthol concentrations ranging from 0.4 to $0.8 \%$ (MIC), but still its MIC value determined for four of the tested strains was as high as $0.8 \%$, and only the C. turicensis lv53 exhibited greater susceptibility. In turn, the value of the maximum concentration of menthol tolerated by the analyzed strains (MTC) ranged from 0.2 to $0.4 \%$.

Next to iso-menthone, limonene, $\beta$-pinene, menthyl acetate, iso-menthanol, and menthofuran, menthol is the main component of an EO from Mentha piperita [37, 45]. No data were found in the literature on the antimicrobial activity of menthol and peppermint EO against Cronobacter, whereas some studies are available on the effect of peppermint EO on the development of other microorganisms and respective results have already been published [34, 37, 43, 44, 68]. Slightly lower MIC values of menthol than these determined in our study were reported by Trombetta et al. [69] for $E$. coli $(\mathrm{MIC}=0.25 \%)$ and by Tyagi and Malik [45] for $E$. coli (MIC $\approx 0.1 \%)$ and for Pseudomonas spp. $(\mathrm{MIC}=0.2 \%)$ but in the case of peppermint EO. Significant morphological alterations (shrunk, deshaped, deformed, and ruptured cells) due to the effect of peppermint oil on B. subtilis have also been observed using a scanning electron microscope [45].

\section{Conclusions}

In summary, this study confirms the antibacterial activity of selected essential oils against Cronobacter. According to analyses conducted with the disc-diffusion method, the most effective EOs were thyme $>$ cinnamon $>$ marjoram. The clove, cumin, and fennel oils had moderately inhibiting effects on only some of the tested strains. The majority of the tested EOs: peppermint, rosemary, basil, cardamom, anise, and ginger as well as all EOs from citrus fruits were ineffective against all the analyzed strains. 
It is difficult to ascribe the antimicrobial effect of an essential oil to one or a few of its active substances, because extracts often contain a mixture of various chemical compounds. Apart from major constituents, also these present in lower or sometimes even trace amounts may significantly contribute to the antimicrobial properties of EO. Nevertheless, in our study, the order of inhibition (based on MIC values) attributed to the tested natural organic compounds was as follows: thymol $>$ trans-cinnamaldehyde $>$ eugenol $>$ menthol, which was also reflected in results obtained for the EOs with the disc-diffusion method (thyme oil > cinnamon oil > peppermint oil).

The use of EOs or natural plant-derived compounds as food additives could be one of the possible ways to control Cronobacter in various types of food products. The use of natural EOs inscribes well into the "clean label" trend and allows reducing amounts of chemical preserving agents. However, further studies addressing their antibacterial activities in food matrices and their effects on the organoleptic properties of food products are required prior to their commercial application.

\section{Compliance with ethical standards}

Conflict of interest The authors declare that they have no conflict of interest.

Compliance with ethics requirements This article does not contain any studies with human or animal subjects.

Open Access This article is distributed under the terms of the Creative Commons Attribution 4.0 International License (http://creativeco mmons.org/licenses/by/4.0/), which permits unrestricted use, distribution, and reproduction in any medium, provided you give appropriate credit to the original author(s) and the source, provide a link to the Creative Commons license, and indicate if changes were made.

\section{References}

1. Fakruddin M, Rahaman MM, Ahmed MM, Hoque MM (2013) Cronobacter sakazakii (Enterobacter sakazakii): an emerging foodborne pathogen. Int J Biomed Adv Res 4:349-359

2. Iversen C, Mullane N, McCardell B, Tall BD, Lehner A, Fanning S, Stephan R, Joosten H (2008) Cronobacter gen. nov., a new genus to accommodate, the biogroups of Enterobacter sakazakii, and proposal of Cronobacter sakazakii gen. nov., comb. nov. Cronobacter malonaticus sp. nov., Cronobacter turicensis sp. nov., Cronobacter muytjensii sp. nov., Cronobacter dublinensis sp. nov., Cronobacter genomospecies 1, and of three subspecies, Cronobacter dublinensis subsp. dublinensis subsp. nov., Cronobacter dublinensis subsp. lausannensis subsp. nov. and Cronobacter dublinensis subsp. lactaridi subsp nov. Int J Syst Evol Micr 58:1442-1447

3. Joseph S, Cetinkaya E, Drahovska H, Levican A, Figueras MJ, Forsythe SJ (2012) Cronobacter condimenti sp. nov., isolated from spiced meat and Cronobacter universalis sp. nov., a novel species designation for Cronobacter sp. genomospecies 1, recovered from a leg infection, water, and food ingredients. Int J Syst Evol Micr 62:1277-1283

4. Forsythe SJ (2018) Updates on the Cronobacter genus. Annu Rev Food Sci Technol 9:23-44

5. Holy O, Forsythe SJ (2014) Cronobacter species as emerging causes of healthcare-associated infection. J Hosp Infect 86:169-177

6. Patrick ME, Mahon BE, Greene SA, Rounds J, Cronquist A, Wymore K, Boothe E, Lathrop S, Palmer A, Bowen A (2014) Incidence of Cronobacter spp. infections, United States, 2003-2009. Emerg Infect Dis 20:1520-1523

7. Yan QQ, Condell O, Power K, Butler F, Tall BD, Fanning S (2012) Cronobacter species (formerly known as Enterobacter sakazakii) in powdered infant formula: a review of our current understanding of the biology of this bacterium. J Appl Microbiol 113:1-15

8. Iversen C, Lane M, Forsythe SJ (2004) The growth profile, thermotolerance and biofilm formation of Enterobacter sakazakii grown in infant formula milk. Lett Appl Microbiol 38:378-382

9. Lehner A, Riedel K, Eberl L, Breeuwer P, Diep B, Stephan R (2005) Biofilm formation, extracellular polysaccharide production, and cell-to-cell signaling in various Enterobacter sakazakii strains: aspects promoting environmental persistence. J Food Prot 68:2287-2294

10. Lee SY, Jin HH (2008) Inhibitory activity of natural antimicrobial compounds alone or in combination with nisin against Enterobacter sakazakii. Lett Appl Microbiol 47:315-321

11. Osaili TM, Al-Nabulsi AA, Shaker RR, Ayyash MM, Olaimat AN, Al-Hasan A, Qadora AS, Holley KM, R.A (2008) Effects of extended dry storage in powdered infant milk formula on susceptibility of Enterobacter sakazakii to hot water or ionizing irradiation. J Food Prot 71:934-939

12. Singh N, Goel G, Raghav M (2015) Prevalence and characterization of Cronobacter spp. from various foods, medicinal plants, and environmental samples. Curr Microbiol 71:31-38

13. Berthold-Pluta A, Garbowska M, Stefańska I, Pluta A (2017) Microbiological quality of selected ready-to-eat leaf vegetables, sprouts and non-pasteurized fresh fruit-vegetable juices including the presence of Cronobacter spp. Food Microbiol 65:221-230

14. Brandão MLL, Scudeller Umeda N, Jackson E, Forsythe SJ, de Filippis I (2017) Isolation, molecular and phenotypic characterization, and antibiotic susceptibility of Cronobacter spp. from Brazilian retail foods. Food Microbiol 63:129-138

15. Chap J, Jackson P, Siqueira R, Gaspar N, Quintas C, Park J, Osaili T, Shaker R, Jaradat Z, Hartantyo SHP, Andullah Sani N, Estuningsih S, Forsythe SJ (2009) International survey of Cronobacter sakazakii and other Cronobacter spp. in follow up formulas and infant foods. Int J Food Microbiol 136:185-188

16. Friedemann M (2007) Enterobacter sakazakii in food and beverages (other than infant formula and milk powder). Int J Food Microbiol 116:1-10

17. Garbowska M, Berthold-Pluta A, Stasiak-Różańska L (2015) Microbiological quality of selected spices and herbs including the presence of Cronobacter spp. Food Microbiol 49:1-5

18. Shaker R, Osaili T, Al-Omary W, Jaradat Z, Al-Zuby M (2007) Isolation of Enterobacter sakazakii and other Enterobacter sp. from food and food production environments. Food Control 18:1241-1245

19. Vasconcellos L, Carvalho CT, Overas Tavares R, de Mello Medeiros V, de Oliveira Rosas C, Silva N, J, dos Reis Lopes, Forsythe SM, Brandão SJ, M.L.L (2018) Isolation, molecular and phenotypic characterization of Cronobacter spp. in ready-to-eat salads and foods from Japanese cuisine commercialized in Brazil. Food Res Int 107:353-359 
20. Mozrová $\mathrm{V}$, Břeňová $\mathrm{N}$, Mrázek $\mathrm{J}$, Lukešová $\mathrm{D}$, Marounek $\mathrm{M}$ (2014) Surveillance and characterisation of Cronobacter spp. in Czech retail food and environmental samples. Folia Microbiol 59:63-68

21. Jayasena DD, Cheorun J (2013) Essential oils as potential antimicrobial agents in meat and meat products: a review. Trends Food Sci Technol 34:96-108

22. Ribeiro-Santos R, Andrade M, Ramos de Melo N, Sanches-Silva A (2017) Use of essential oils in active food packaging: recent advances and future trends. Trends Food Sci Technol 61:132-140

23. Burt S (2004) Essential oils: their antibacterial properties and potential applications in foods - a review. Int J Food Microbiol 94:223-253

24. Johny AK, Darre M, Donoghue A, Donoghue D, Venkitanarayanan K (2010) Antibacterial effect of trans-cinnamaldehyde, eugenol, carvacrol, and thymol on Salmonella Enteritidis and Campylobacter jejuni in chicken cecal contents in vitro. J Appl Poult Res 19:237-244

25. Fisher K, Phillips CA (2006) The effect of lemon, orange and bergamot essential oils and their components on the survival of Campylobacter jejuni, Escherichia coli $\mathrm{O} 157, \mathrm{~L}$ B a S in vitro and in food systems. J Appl Microbiol 101:1232-1240

26. Kim SA, Rhee MS (2016) Highly enhanced bactericidal effects of medium chain fatty acids (caprylic, capric, and lauric acid) combined with edible plant essential oils (carvacrol, eugenol, b-resorcylic acid, trans-cinnamaldehyde, thymol, and vanillin) against Escherichia coli O157:H7. Food Control 60:447-454

27. Mattson TE, Johny AK, Amalaradjou MAR, More K, Schreiber DT, Patel J, Venkitanarayanan K (2011) Inactivation of Salmonella spp. on tomatoes by plant molecules. Int J Food Microbiol 144:464-468

28. Ojeda-Sana AM, van Baren CM, Elechosa MA, Juárez MA, Moreno S (2013) New insights into antibacterial and antioxidant activities of rosemary essential oils and their main components. Food Control 31:189-195

29. Tajkarimi MM, Ibrahim SA, Cliver DO (2010) Antimicrobial herb and spice compounds in food. Food Control 21:1199-1218

30. Thippeswamy NB, Naidu KA, Achur RN (2013) Antioxidant and antibacterial properties of phenolic extract from Carum carvi $\mathrm{L}$. J Pharm Res 7:352-357

31. Al-Nabulsi AA, Awaisheh SS, Osaili TM, Olaimat AN, Rahahaleh RJ, Al-Dabbas FM, Al-Kharabsheh LA, Gyawali R, Ibrahim SA (2015) Inactivation of Cronobacter sakazakii in reconstituted infant milk formula by plant essential oils. J Appl Bot Food Qual 88:97-101

32. Amalaradjou MA, Hoagland TA, Venkitanarayanan K (2009) Inactivation of Enterobacter sakazakii in reconstituted infant formula by trans-cinnamaldehyde. Int J Food Microbiol 129:146-149

33. Fraňková A, Marounek M, Mozrová V, Weber J, Klouček P, Lukešová D (2014) Antibacterial activities of plant-derived compounds and essential oils toward Cronobacter sakazakii and Cronobacter malonaticus. Foodborne Pathog Dis 11:795-797

34. Rusenova N, Parvanov P (2009) Antimicrobial activities of twelve essential oils against microorganisms of veterinary importance. Trakia J Sci 7(1):37-43

35. Oussalah M, Caillet S, Saucier L, Lacroix M (2007) Inhibitory effects of selected plant essential oils on the growth of four pathogenic bacteria: E. coli O157:H7, Salmonella Typhimurium, Staphylococcus aureus and Listeria monocytogenes. Food Control 18:414-420

36. Santurio DF, Kunz de Jesus FP, Zanette RA, Schlemmer KB, Fraton A, Fries M, L.L (2014) Antimicrobial activity of the essential oil of thyme and of thymol against Escherichia coli strains. Acta Sci Vet 42:1234

37. Soković M, Glamoclija J, Marin PD, Brikić D, Van Griensven LJLD (2010) Antibacterial effects of the essential oils of commonly consumed medicinal herbs using an in vitro model. Molecules 15:7532-7546

38. Xu J, Zhou F, Ji B-P, Pei R-S, Xu N (2008) The antibacterial mechanism of carvacrol and thymol against Escherichia coli. Lett Appl Microbiol 47:174-179

39. Vasconcelos NG, Croda J, Simionatto S (2018) Antibacterial mechanisms of cinnamon and its constituents: a review. Microb Pathogenesis 120:198-203

40. Ooi LSM, Li Y, Kam S-L, Wang H, Wong EYL, Ooi VEC (2006) Antimicrobial activities of cinnamon oil and cinnamaldehyde from the chinese medicinal herb Cinnamomum cassia Blume. Am J Chin Med 34:511-522

41. Hu Q, Zhou M, Wei S (2018) Progress on the antimicrobial activity research of clove oil and eugenol in the food antisepsis field. $\mathrm{J}$ Food Sci 83:1476-1480

42. Singh N, Patil A, Prabhune A, Goel G (2016) Inhibition of quorum-sensing-mediated biofilm formation in Cronobacter sakazakii strains. Microbiology 162:1708-1714

43. Eteghad SS, Mirzaei M, Pour SF, Kahnamui S (2009) Inhibitory Effects of endemic Thymus vulgaris and Mentha piperita essential oils on Escherichia coli O157:H7. Res J Biol Sci 4:340-344

44. Jeyakumar E, Lawrence R, Pal T (2011) Comparative evaluation in the efficacy of peppermint (Mentha piperita) oil with standards antibiotics against selected bacterial pathogens. Asian Pac J Trop Biomed 1(2 Suppl):S253-S257. https://doi.org/10.1016/S2221 -1691(11)60165-2

45. Tyagi AK, Malik A (2011) Antimicrobial potential and chemical composition of Mentha piperita oil in liquid and vapour phase against food spoiling microorganisms. Food Control 22:1707-1714

46. Tserennadmid R, Takó M, Galgóczy L, Papp T, Vágvölgyi C, Gerő L, Krisch J (2010) Antibacterial effect of essential oils and interaction with food components. Cent Eur J Biol 5:641-648

47. Razzaghi-Abyaneh M, Shams-Ghahfarokhi M, Rezaee M-B, Jaimand K, Alinezhad S, Saberi R, Yoshinari T (2009) Chemical composition and antiaflatoxigenic activity of Carum carvi L. Thymus vulgaris and Citrus aurantifolia essential oils. Food Control 20:1018-1024

48. Del Campo J, Amiot MJ, Nguyen-The C (2000) Antimicrobial effect of rosemary extracts. J Food Prot 63:1359-1368

49. Jiang Y, Wu N, Fu Y-J, Wang W, Luo M, Zhao Ch-J, Zu J-G, Liu X-L (2011) Chemical composition and antimicrobial activity of the essential oil of Rosemary. Environ Toxicol Pharm 32:63-68

50. Dadalioglu I, Evrendilek GA (2004) Chemical compositions and antibacterial effects of essential oils of Turkish oregano (Origanum minutiflorum), bay laurel (Laurus nobilis), Spanish lavender (Lavandula stoechas L.), and fennel (Foeniculum vulgare) on common foodborne pathogens. J Agric Food Chem 52:8255-8260

51. Rather MA, Dar BA, Sofi SN, Bhat BA, Qurishi MA (2016) Foeniculum vulgare: a comprehensive review of its traditional use, phytochemistry, pharmacology, and safety. Arab J Chem 9:S1574-S1583

52. Cantore PL, Iacobelli NS, Marco AD, Capasso F, Senatore F (2004) Antibacterial activity of Coriandrum sativum L. and Foeniculum vulgare Miller Var. vulgare (Miller) essential oils. J Agric Food Chem 52:7862-7866

53. Mohsenzadeh M (2007) Evaluation of antibacterial activity of selected Iranian essential oils against Staphylococcus aureus and Escherichia coli in nutrient broth medium. Pak J Biol Sci 10:3693-3697

54. Elgayyar M, Draughon FA, Golden DA, Mount JR (2001) Antimicrobial activity of essential oils from plants against selected pathogenic and saprophytic microorganisms. J Food Prot 64:1019-1024

55. Shi C, Song K, Zhang X, Sun Y, Sui Y, Chen Y, Jia Z, Sun H, Sun Z, Xia X (2016) Antimicrobial activity and possible mechanism 
of action of citral against Cronobacter sakazakii. PLoS One 11 (7):e0159006. https://doi.org/10.1371/journal.pone.0159006

56. Inouye S, Yamaguchi H, Takizawa T (2001) Screening of the antibacterial effects of variety of essential oils on respiratory tract pathogens, using dilution assay method. J Infect Chemother 7:251-254

57. Bellik Y (2014) Total antioxidant activity and antimicrobial potency of the essential oil and oleoresin of Zingiber officinale Roscoe. Asian Pac J Trop Dis 4:40-44

58. Konakchiev A, Damyanova S, Stoilova I, Thi SP (2006) Composition and antimicrobial activity of ginger essential oil from Vietnam. J Essent Oil Bearing Plants 9(1):93-98

59. Olasupo NA, Fitzgerald DJ, Gasson MJ, Narbad A (2003) Activity of natural antimicrobial compounds against Escherichia coli. and Salmonella enterica serovar Typhimurium. Lett Appl Microbiol 37:448-451

60. Pei RS, Zhou F, Ji BP, Xu J (2009) Evaluation of combined antibacterial effects of eugenol, cinnamaldehyde, thymol, and carvacrol against $E$. coli with an improved method. J Food Sci 74:379-383

61. Amalaradjou MA, Venkitanarayanan K (2011) Effect of transcinnamaldehyde on reducing resistance to environmental stresses in Cronobacter sakazakii. Foodb Pathog Dis 8:403-409

62. Domadia P, Swarup S, Bhunia A, Sivaraman J, Dasgupta D (2007) Inhibition of bacterial cell division protein FtsZ by cinnamaldehyde. Biochem Pharmacol 74:831-840

63. Amalaradjou MA, Venkitanarayanan K (2011) Effect of transcinnamaldehyde on inhibition and inactivation of Cronobacter sakazakii biofilm on abiotic surfaces. J Food Prot 74:200-208
64. Hill LE, Gomes C, Taylor TM (2013) Characterization of betacyclodextrin inclusion complexes containing essential oils (transcinnamaldehyde, eugenol, cinnamon bark, and clove bud extracts) for antimicrobial delivery applications. LWT-Food Sci Technol 51:86-93

65. Ye H, Shen S, Xu J, Lin S, Yuan Y, Jones GS (2013) Synergistic interactions of cinnamaldehyde in combination with carvacrol against food-borne bacteria. Food Control 34:619-623

66. Devi KP, Nisha SA, Sakthivel R, Pandian SK (2010) Eugenol (an essential oil of clove) acts as an antibacterial agent against Salmonella typhi by disrupting the cellular membrane. J Ethnopharmacol 130:107-115

67. Filgueiras CT, Vanetti MCD (2006) Effect of eugenol on growth and listeriolysin O production by Listeria monocytogenes. Braz Arch Biol Techn 49:405-409

68. Iscan G, Kirimer R, Kurckuoglu M, Can Baser H, Demirci K, F (2002) Screening of Mentha piperita essential oils. J Agric Food Chem 50:3943-3946

69. Trombetta D, Castelli F, Sarpietro MG, Venuti V, Cristani M, Daniele C, Saija S, Mazzanti G, Bisignano G (2005) Mechanisms of antibacterial action of three monoterpenes. Antimicrob Agents Chemother 49:2474-2478

Publisher's Note Springer Nature remains neutral with regard to jurisdictional claims in published maps and institutional affiliations. 